\title{
Free Will Skepticism and the Question of Creativity: Creativity, Desert, and Self-Creation
}

GREGG D. CARUSO

$\mathrm{F}$ REE WILL SKEPTICISM maintains that what we do, and the way we are, is ultimately the result of factors beyond our control and that because of this we are never morally responsible for our actions in the basic desert sense-the sense that would make us truly deserving of praise and blame. In recent years, a number of contemporary philosophers have advanced and defended versions of free will skepticism, including Derk Pereboom (2001; 2014), Galen Strawson (2010), Neil Levy (2011), Bruce Waller (2011; 2015), and myself (Caruso 2012; 2013; in press). Critics, however, often complain that adopting such views would have dire consequences for ourselves, society, morality, meaning, and the law. They fear, for instance, that relinquishing belief in free will and basic desert moral responsibility would leave us unable to adequately deal with criminal behavior, increase anti-social conduct, and undermine meaning in life.

In response, free will skeptics argue that life without free will and basic desert moral responsibility would not be as destructive as many people believe (see, e.g., Pereboom 2001; 2014; Waller 2011; 2015; Caruso 2016; in press). According to optimistic skeptics, prospects of finding meaning in life or of sustaining good interpersonal relationships, for instance, would not be threatened. And although retributivism and severe punishment, such as the death penalty, would be ruled out, incapacitation and rehabilitation programs would still be justified (see Pereboom 2001; 2013; 2014; Levy 2012; Caruso 2016; Pereboom \& Caruso in press). In this paper, I attempt to extend this general optimism about the practical implications of free will skepticism to the question of creativity.

In Section 1, I spell out the question of creativity and explain why it's relevant to the problem of free will. In Section 2, I identify three different conceptions of creativity and explain the practical concerns critics have with free will skepti-

Contact: Gregg Caruso <gcaruso@corning-cc.edu> 
cism. In Section 3, I distinguish between three different conceptions of moral responsibility and argue that at least two of them are consistent with free will skepticism. I further contend that forward-looking accounts of moral responsibility, which are perfectly consistent with free will skepticism, can justify calling agents to account for immoral behavior as well as providing encouragement for creative activities since these are important for moral and creative formation and development. I conclude in Section 4 by arguing that relinquishing belief in free will and basic desert would not mean the death of creativity or our sense of achievement since important and realistic conceptions of both remain in place.

\section{The Question of Creativity}

One aspect of the traditional free will debate that is often overlooked is the question of creativity-i.e., whether free will is required for genuine creativity and whether agents justly deserve to be praised and blamed for their artistic and creative achievements. Historically, philosophical discussions of free will have tended to narrowly focus on moral responsibility, but the issue of free will is of broader interest than this since it concerns the ways in which human action and activities are embedded in the natural order of events. As Paul Russell writes,

All of us aspire to be something more than simply moral agents. We want freedom because we also value a certain conception of ourselves as agents who secure and bring into existence values other than moral values by means of the exercise of our own agency. Perhaps nothing manifests this concern more evidently than artistic activity .... Through artistic activities of various kinds we create valuable and worthwhile things and events by means of our agency. Moreover, activities of this kind serve as the basis of evaluations of agents (i.e., artists) and their works (i.e., performances and creations). For this reason, the problem of "free will" is directly involved here. (2008: 308)

Robert Kane further highlights the desire many have for self-creation:

Among the creations we wish to be 'our own,' one stands out as particularly important-our own 'self'." Free will has been traditionally conceived as a kind of creativity (poiesis, in the language of the ancient Greek thinkers) akin to artistic creativity, but in which the work of art created is one's own self. As ultimate creators of some of our own ends or purposes, we are the designers of our own lives, self-governing, self-legislatingmasters, to some degree, of our own moral destinies. (1996: 81) 
While almost everyone acknowledges that questions about free agency matter to our moral responsibility practices and the meaning and significance of our lives, surprisingly little has been said about our sense of creative agency. This is surprising since the question of creativity seems directly relevant to the problem of free will because it raises important questions about human agency, ability and effort, assessment and evaluation, just deserts, and reward and punishment.

Artistic activities, for instance, involve factors intrinsic to the agent such as developing their talents or taking advantage of their abilities. As Russell notes, "being good at the piano is not a matter of pure luck-unlike, say, being born with beautiful green eyes" (2008: 309). While we may acknowledge the role luck plays in terms of innate gifts, opportunities, and artistic achievements (e.g., awards and recognitions), we nonetheless believe that agents are capable of exercising effort and working hard to develop their artistic skills and abilities. The fact that Wolfgang Amadeus Mozart was born into a musical family with a father who was a professional musician, does not change the fact that he needed to take advantage of this opportunity and work hard to develop his musical talent. Mozart's ability to exercise such effort in the development of his talent, however, raises important questions about human agency and control-for example, does Mozart need to be responsible for the formation of his own character (the kind of character that led him to exert such effort), or is it enough that he simply acted in accordance with his character (even if his character was formed by factors beyond his control)? The development of artistic talent therefore raises many of the same questions as moral development and thus the same questions regarding free will can arise for both.

Switching to the perspective of the spectator, artistic activities also invite us to take up what Paul Russell calls the "evaluative stance" toward the agent as well as the performance, creation, or product (2008: 310). Human beings not only evaluate the moral actions of their fellows, they also evaluate their artistic activities. We may say of a work of art or performance that it was done well or poorly and we may administer rewards and punishments in response to it. As Russell points out, "these features of our evaluative stance may take various forms, ranging from (expressed) approval/disapproval, to prizes and awards, promotions or demotions, humiliation and ridicule, titles and honors, and-in the more weighty cases-legal sanction such as prison, corporal or even capital punishment" (2008: 310). And when we take up the evaluative stance, the system of retributive attitudes and practices vary in strength and degree, depending on the nature of the activity involved (2008: 310). Furthermore, we need to recognize that the evaluative stance is not limited to the artistic performance or creation, rather it goes down deeper to the qualities of the agent considered as the source of the performance: "Great performances and achievements secure rewards and prizes, criticism and condemnation, for the person who produced 
them. It is the agent who receives whatever retributive response is called forth by her activities or performance" (Russell 2008: 310). This is obvious and familiar in the arts where it is the actor who takes home the Oscar or the 'genius' artist who receives the praise.

What I'm calling the question of creativity should therefore be understood as the question of what conditions are required for genuine creativity and whether agents justly deserve to be praised and blamed for their creative and artistic activities. Since these questions are intimately wrapped up in the problem of free will, all parties in the debate should explain how they would address them. This paper is my attempt to explain how a free will skeptic would go about doing so.

\section{Three Concepts of Creativity}

In attempting to answer these questions, it's helpful to distinguish between three different concepts of creativity. The first, which I will call L-creativity, employs a libertarian conception of free will and is rooted in the notion of underived origination. Kane defines underived origination as follows (1996: 79). An agent is capable of underived origination if and only if: (1) the source or ground (arche) of action is in the agent or self, and not outside the agent. This means that (2) if we were to trace the causal or explanatory chain of action backward to their sources, they would terminate in actions that can only and finally be explained in terms of agent's voluntarily or willingly performing them (i.e., in what Kane calls self-forming actions or SFAs; see Kane 1996). (3) The agent is the sole author or underived originator of these self-forming actions and is thereby ultimately responsible to some degree for the self which was formed by them and for subsequent actions issued from the self. And (4) these self-forming actions are not determined by anything within or outside the self for which the agent was in no way responsible.

L-creativity claims that the underived origination required by libertarian free will is a necessary condition for genuine creativity in the universe (see Kane 1996: 81). Proponents of L-creativity can be found throughout the incompatibilist literature. William Barrett, for instance, writes,

Determinism is a position repugnant to most people. Why is this? . . one of the main motives in the rebellion against determinism, not only on the part of ordinary people but also of most modern philosophers who have been vigorously opposed to the determinist position: namely, the desire for freshness, novelty, genuine creation-in short, an open rather than a closed universe. Such is the main impulse in the criticism of determinism by philosophers like Pierce, James, Bergson, Whitehead, and Dewey. (1958: 46, emphasis added). 
W. S. Anglin similarly argues that creativity in the arts and other human activities presupposes the underived origination that is characteristic of libertarian free will (Kane 1996: 81). He writes,

[On this] view of what it is to create ... one brings forth something that is not implicit in the past. The circumstances of the artist influences him, of course, but they do not supply that particular vision of insight that becomes the work of art. It is not nature or God, but simply the composer who creates the symphony. One need not expect ... that any person ... with character and musical abilities similar to those of Beethoven ... would write down exactly the same notes as Beethoven wrote down [when he composed the Fifth Symphony]. Beethoven himself in that situation, might well have composed a different symphony, or no symphony at all. (1990: 14, as quoted in Kane 1996: 81)

According to L-creativity, then, for Beethoven to be the creative genius of the Fifth Symphony he must be the ultimate source of the composition and satisfy the conditions for underived origination.

It is here where concerns over the implications of free will skepticism arise. L-creativity theorists worry that if we lack libertarian free will and underived origination, our artistic activities and achievements would be impoverished in two especially significant respects (see Russell 2008: 311-313). First, they worry that we would lack freshness, novelty, and genuine creativity (Kane 1996: 81). As Russell describes, "The general worry here is that 'novelty' and 'genuine creativity' presuppose a metaphysical picture of things where the source of performances or artistic objects must in some required way transcend the antecedent conditions from which they arise" (2008: 311). That is, for the libertarian, creative acts "must be original in the sense that they cannot be (fully) explained or accounted for by the circumstances or conditions in which they come into being" (2008: 311).

The second worry L-creativity theorists have is that, if agents were not capable of this kind of creativity there would be no "true desert for one's achievements" (Kane 1996: 82). Kane, for instance, argues that if there were circumstances that completely determine and explain our creative and artistic activities, then "the outcome would be a matter of luck" and the agent would be denied all sense of "accomplishment." For L-creativity theorists, "accomplishment" and the associated requirements of "true desert" demand what Kane describes as the "kind of sole authorship" or "underived origination that many ordinary persons believe they want when they want free will" (1996: 70; as quoted in Russell 2008: 312).

There are, however, less demanding conceptions of creativity. Compatibilists, for example, do not demand underived origination or the unconditional 
ability to do otherwise for agents to justly deserve praise and blame for moral and artistic actions and activities. A compatibilist conception of creativity-which we can call C-creativity for short-would therefore maintain that genuine creativity, and the desert associated with it, does not require ultimate authorship or underived origination. Consider again the Mozart example. Let us assume for the moment that a combination of internal and external factors were such that his compositions and performances were fully determined. ${ }^{1}$ That is, let us assume that Mozart's compositions and performances could be fully and causally explained in terms of antecedent conditions and circumstances ultimately beyond his control. Would there be genuine creativity and novelty in such a situation? Would Mozart justly deserve to be praised and blamed, rewarded and punished, for his compositions and performances? Could we credit Mozart with creativity and originality?

L-creativity theorists would say no. C-creativity theorists, however, do not see determinism as a threat to genuine creativity and its cognate concepts. Here, for example, is Russell discussing originality and freshness in the Mozart case:

To judge whether or not Mozart's works are "original," "fresh," etc., we must compare them to other works. It is the performance/composition by Mozart as compared with other (earlier) works that serves as the relevant basis for any judgment of this kind (i.e., is it "new," "original," etc.?). Even if there exists deterministic causal paths leading to the emergence of Mozart's works ..., none of this would serve to show that the works concerned are not "creative," "original" or "new contributions" to the evolution of Western music. Clearly, the presence or absence of libertarian free will cannot decide this issue one way or the other. (2008: 312$)$.

Russell's point is that judgments about originality, novelty, and freshness are unaffected by the truth or falsity of determinism. Rather, they are comparative terms that judge an artistic performance, creation, or product in terms of its relation to other works. Mozart's symphonies can justifiably be called "new" and "original" to the extent that they introduce previously unheard themes, methods, arrangements, etc. Such a conception of originality and novelty would not therefore require libertarian free will.

An L-creativity theorist could still argue, however, that even if we grant this point about originality, worries about merit and just deserts still remain in place. Given our assumption of determinism and lack of underived origination, they would argue that all praise of Mozart (the artist/person) would be shallow or superficial and any rewards and honors we bestow upon him would not be truly

1. This example is drawn from Russell (2008: 312-313). 
deserved. As Russell writes, "According to incompatibilists, such as Kane, if the deterministic story that has been told about Mozart's life is true, then Mozart was simply lucky - the fortunate causal vehicle for forces and factors that work their way through him but do not begin with him" (2008: 313). In reply to this, compatibilists typically argue that incompatibilists are demanding too much and that true desert-including justified praise and blame, punishment and reward-is perfectly consistent with determinism. They hold that what is of utmost importance is not the falsity of determinism, nor that our actions are uncaused, but that our actions are voluntary, free from constraint and compulsion, and caused in the appropriate way. Different compatibilist accounts spell out the exact requirements for compatibilist freedom differently but popular theories tend to focus on such things as reasons-responsiveness, guidance control, hierarchical integration, and approval of one's motivational states. A C-creativity theorist would therefore argue that even if Mozart did not make himself in the libertarian sense of self-creation, he still deserves praise and blame, punishment and reward, for his compositions and performances. A compatibilist conception of creativity (C-creativity) therefore maintains that determinism does not threaten merit and desert.

There is, however, a third conception of creativity, one that is in agreement with C-creativity on originality, novelty, and freshness, but not on just deserts and merit. We can call this conception S-creativity since it is consistent with skepticism about free will and basic desert moral responsibility. S-creativity maintains that originality, novelty, and freshness are perfectly consistent with determinism (and the denial of free will more generally) since these notions are, as Russell argues, comparative terms. According to S-creativity, while all art is derivative to some extent, we can nevertheless judge originality and novelty on a relative scale. Miles Davis and Jackson Pollock can be said to be original artists who produced novel works because their performances and creations differed significantly from those who came before them. Those artists, on the other hand, whose performances, creations, or products resemble those of their predecessors, or are otherwise more derivative, would be considered less original.

S-creativity, however, differs from C-creativity in that it relinquishes the notion that agents justly deserve to be praised and blamed for their artistic activities. And this is because one of the defining features of free will skepticism is that it denies basic desert moral responsibility-i.e., the kind of moral responsibility needed to make us truly deserving of praise and blame in a backward-looking, non-consequentialist sense (see Pereboom 2001; 2014; Strawson 1994; Levy 2011; Caruso \& Morris in press). Adopting the skeptical perspective would therefore have important implications for the question of creativity. We would need to recognize that free will skepticism is incompatible with both L-creativity and C-creativity. It is incompatible with L-creativity because it maintains that the conditions for libertarian free will and underived origination can never be prop- 
erly satisfied. And it is incompatible with C-creativity because it maintains that the causal determination of our actions by natural factors beyond our control, including creative actions and activities, cannot be reconciled with the idea that individuals justly deserve praise and blame, reward and punishment.

While critics fear that relinquishing these notions would undermine everyday judgments and practices regarding creativity, such fears are based on the assumption that free will and basic desert moral responsibility are needed for creativity. But are they? I will now argue that S-creativity can preserve enough of what we care about and that life without free will would not be as destructive to creativity as many people believe.

\section{Accountability, Attributability, and Answerability}

To begin, it is important to distinguish between three distinct conceptions of responsibility that have been identified in the literature: accountability, attributability, and answerability (see, e.g., Watson 1996; Shoemaker 2011; Eshleman 2014).

Drawing on P.F. Strawson's (1962) work, contemporary accountability theorists maintain that to be responsible is to be an apt candidate for the reactive attitudes-including resentment, indignation, guilt, blame, and moral anger (Bennett 1980; Wallace 1994; Watson 1996; Fischer \& Ravizza 1998; Darwall 2006). In other words, an agent is responsible, if and only if it is appropriate for us to hold her responsible, or accountable, via the reactive attitudes. But since the reactive attitudes can cause harm, say in the case of blaming attitudes and practices, they would seem to be appropriate only if it is fair that the agent be subject to them in the sense that she deserve them. We can say, then, that an agent is accountable for her action when she deserves, in the basic desert sense, to be praised or blamed for what she did-i.e., she deserves certain kinds of desert-based judgments, attitudes, or treatments in response to decisions or actions she performed or failed to perform, and these judgments, attitudes, or treatments are justified on purely backward-looking grounds and do not appeal to consequentialist or forward-looking considerations, such as future protection, future reconciliation, or future moral formation.

As we've seen, free will skepticism rejects this kind of moral responsibility since accountability is either coextensive with, or heavily relies upon, the notion of basic desert. There are, however, accounts of responsibility that make no essential reference to the reactive attitudes or to the notion of basic desert. Attributability responsibility, for instance, is about actions or attitudes being properly attributable to, or reflective of, an agent's self. That is, we are responsible for our actions in the attributability sense only when those actions reflect our identities as moral agents, i.e., when they are attributable to us. As Gary Watson has 
highlighted, the central concern in such views is whether the agent's action or attitude discloses her evaluative judgments or commitments (1996; see also Eshleman 2014). Since attributability makes no appeal to basic desert or backwardlooking praise and blame, it remains independent of accountability (see Shoemaker 2011; Watson 1996). As Andrew Eshleman explains,

Satisfying some baseline conditions of responsibility as attributability would appear to be necessary in order to be responsible in the sense of accountable. For example, it would seem unfair to hold someone accountable for an action via reactive attitudes such as resentment or indignation, if the action was not properly attributable to the agent-say, because she succumbed to a genuinely coercive psychological compulsion. Yet being responsible in the attributability sense is not sufficient for being responsible in the accountability sense. (2014)

Given this, it is available for free will skeptics to endorse attributability without inconsistency.

The third conception of responsibility, so-called answerability, does not fit into either of these two categories. According to this concept of responsibility, someone is responsible for an action or attitude just in case it is connected to her capacity for evaluative judgment in a way that opens her up, in principle, to demands for justification from others (Oshana 1997; Scanlon 1998; Bok 1998; Pereboom 2014). When we encounter apparently immoral behavior, for example, it is perfectly legitimate to ask the agent, "Why did you decide to do that?" or "Do you think it was the right thing to do?" If the reasons given in response to such questions are morally unsatisfactory, we regard it as justified to invite the agent to evaluate critically what her actions indicate about her intentions and character, to demand an apology, or to request reform. According to Derk Pereboom (2014), engaging in such interactions is reasonable in light of the right of those harmed or threatened to protect themselves from immoral behavior and its consequences. In addition, we might have a stake in reconciliation with the wrongdoer, and calling her to account in this way can function as a step toward realizing this objective. We also have an interest in her moral formation, and the address described naturally functions as a stage in this process (see Pereboom 2014).

Answerability, I contend, is perfectly consistent with free will skepticism as long as it is understood in the way that Pereboom has recently articulated it (see Pereboom 2014). On Pereboom's account, blame is grounded, not in basic desert, but in three non-desert invoking moral desiderata: protection of potential victims, reconciliation both of personal relationships and with the moral community more generally, and moral formation. A forward-looking account of answerability-responsibility grounded in future protection, future reconcilia- 
tion, and future moral formation is in harmony with free will skepticism since it does not appeal to basic desert in any way.

I believe this account of forward-looking answerability can, with perhaps minor modification, be applied equally well to cases of creative actions and choices. If we disapprove of an agent's creative decision, for example, it is perfectly legitimate to ask the agent, "Why did you decide to do that?" or "Do you think it was the right creative choice?" If, for example, we disapprove of Bob Dylan's decision to go electric at the Newport Folk Festival in 1965, it would have been appropriate for us to question his decision and request an explanation. If we were not satisfied with his explanation, either morally or aesthetically, we could invite Dylan to critically evaluate his actions, intentions, and character, and even request reform. While the purpose of this conversational exchange would not be safety or protection, as it was in the moral case, reconciliation and creative development remain legitimate forward-looking aims. In fact, at the time of Dylan's decision to go electric, many of his fans felt hurt and betrayed. Holding Dylan answerable for his choice could help reconcile his relationship with his fanseither through Dylan acknowledging a mistake on his part and working to correct it, or (as was largely the case) his audience coming to accept his reasons for action.

This is not to say, of course, that safety and protection cannot also serve as forward-looking grounds for holding someone creatively answerable. A musician, for example, who denigrates women and perpetuates and glorifies rape culture puts women at risk. It jeopardizes women's safety by encouraging societal attitudes about gender and sexuality that attempt to normalize rape. Since we have a right to protect ourselves and others from future harm, forwardlooking answerability justifies us calling this musician to account. In so doing, we request an explanation for the sexist and denigrating behavior with the intent of having the agent acknowledge a disposition to act badly, and then, if he has in fact so acted without excuse or justification, we aim for him to come to see that the disposition issuing in the action is best eliminated. This can all be done without appealing to backward-looking blame or basic desert moral responsibility.

In addition to future reconciliation and future protection, creative development also requires agents to reflect upon their reasons for action and to be able to articulate sound justifications. Holding agents answerable for their creative choices therefore serves an important forward-looking function in developing these skills. It is not uncommon for art students, for example, to participate in classroom 'critiques' - a conversational strategy used to analyze, describe, and interpret works of art. The purpose of these critiques is to help students develop their interpretive, evaluative, and justificatory skills. Such skills are beneficial to agents whether or not they intend on becoming artists. When we hold students 
answerable in this way, we do so not to exact retribution but to develop in them important skills moving forward. These skills include improved self-awareness, improved ability to articulate sound reasons for action, and improved ability to adjust one's actions in light of legitimate criticism and feedback. Since developing creativity in the arts and other human activities benefits society in innumerable ways, I contend that we are justified in holding agents responsible in the forward-looking answerability sense.

A critic may question what form blame will take absent overt expressions of moral resentment and indignation and whether it will be effective, but here I follow Pereboom in arguing that: ( 1 ) there are alternative attitudes expression of which are not linked with beliefs about basic desert, and communication of which can be as effective morally as expressions of resentment and indignation; and (2) in certain important respects blame without expression of these reactive attitudes is to be preferred (see Pereboom 2001; 2014). For example, when someone is mistreated in a relationship, there are other emotions available besides resentment and indignation-these emotions include "feeling disappointed, hurt or shocked about what the offender has done, moral concern for him, and moral sadness and sorrow generated by this concern when the harm done is serious" (Pereboom 2014: 146). Communicating such disappointment, sadness, or concern can be quite effective in motivating avoidance of future misbehavior. In addition, communication of such alternatives to resentment and indignation "is not typically aggressive in the way that expression of anger can be, and will usually not have its intimidating effect" (Pereboom 2014: 147). Furthermore, adopting this skeptical account of moral responsibility has the potential benefit of relinquishing us of an often-destructive form of moral anger (see Pereboom 2001; 2014).

In the creative and artistic examples just discussed, I maintain that engaging agents in a conversation about their decisions and holding them to account in a way that avoids expression of moral resentment and indignation would not only be more effective, it would also be more appropriate. For instance, it's appropriate to express disappointment, hurt, or shock at Dylan's decision to go electric, but it would seem inappropriate to express the reactive attitudes of resentment and indignation. Furthermore, expressions of moral anger have the potential of undermining any attempt at reconciliation. The same I contend is true in the case of classroom critiques of art students. Expression of moral anger, resentment, and indignation would not only be inappropriate, it would also be counterproductive from the perspective of encouraging and developing creative skills. To the extent, then, that we care at all about future protection, reconciliation, and creative development, the alternative attitudes discussed above would be preferable. 


\section{Creativity and Optimistic Skepticism}

We have just seen that there are at least two distinct kinds of responsibility that are consistent with free will skepticism: attributability and forward-looking answerability. In this section, I will further explain how these two varieties of responsibility can be put to work to preserve our most important judgments and practices concerning creativity and creative activities. Let me begin with the importance of attributability.

This year we celebrate the centenary of Albert Einstein's discovery of a new theory of gravity-general relativity. It is easy to find in the media statements like the following: "Einstein's achievement required perseverance and enormous creativity, as he struggled over a rough and winding road for eight years to formulate the theory" (Smeenk 2015). Some critics fear that if free will skepticism is true, we would be unable to legitimately attribute "perseverance" and "enormous creativity" to Einstein. There is no reason to think, however, that this would be so. If theses traits were constitutive of Einstein's character, if they were reflective of who he was, then we are warranted in attributing them to Einstein the person. The denial of free will and basic desert moral responsibility does not prohibit us from making such attributions, nor does it prohibit us from acknowledging the important role character plays in determining outcomes. The free will skeptic can recognize that the virtues of Einstein's character were responsible for his great success, including his perseverance and enormous creativity, without also thinking that he was responsible for creating his own character.

In fact, Einstein himself was a free will skeptic who believed that his "enormous creativity" was not of his own making. In a 1929 interview in The Saturday Evening Post, he states, "I am a determinist. As such, I do not believe in free will . . . I believe with Schopenhauer: We can do what we wish, but we can only wish what we must" (1929: 114). He goes on to add: "My own career was undoubtedly determined, not by my own will but by various factors over which I have no control" (1929: 114). He concludes by rejecting the idea that he deserves praise or credit for his creative achievements: "I claim credit for nothing. Everything is determined, the beginning as well as the end, by forces over which we have no control. It is determined for the insect as well as for the star. Human beings, vegetables or cosmic dust, we all dance to a mysterious tune, intoned in the distance by an invisible player" (1929: 117).

The free will skeptic agrees with Einstein that he does not deserve credit or praise in the basic desert sense for his "enormous creativity." Saying this, however, does not prevent us from legitimately ascribing creativity to Einstein. Since desert claims are about accountability and ascriptions of creativity are about attributability, there is no inconsistency in free will skeptics attributing "creativity" to agents. As long as the actions and attitudes we attribute to agents are 
reflective of their evaluative judgments or commitments, the requirements for attributability are satisfied. In Einstein's case, he had a long-standing desire to satisfy his own curiosity about the nature of gravity; he exhibited patience and perseverance in the face of obstacles during his long journey toward the final formulation of general relativity; he played the piano and violin to clear his mind and stimulate his creativity; etc. All of these character traits are reflective of his evaluative judgments and commitments and hence can be legitimately attributed to him. I therefore contend that we can, without inconsistency, say that Einstein was enormously creative and responsible (in the attributability sense) for his creative achievements, without also saying that he was responsible in the accountability sense.

At this point, critics of S-creativity may be willing to concede that attributability is consistent with free will skepticism but nonetheless object that something important is still missing from such an account. If free will skepticism were true, they fear, we would lack the sort of control over our creativity that would allow us to derive fulfillment from our creative projects and pursuits. Furthermore, there would be no "true desert for one's achievements" (Kane 1996: 82) and no sense of accomplishment. While I understand these fears, I believe they are overblown. I acknowledge that adopting the skeptical perspective would mean that agents are never morally responsible in the backward-looking, basic desert sense. I also acknowledge that some loss may be experienced in relinquishing our pre-theoretical beliefs about free will and L-creativity. Giving up the belief in indeterminist free will may be difficult for some, but I contend that it would by no means undermine the fulfilment in life that our creative projects can provide.

For instance, it is not obvious that achievement is tied to praiseworthiness in the strong way assumed by critics. As Pereboom writes, "If one hopes for a certain outcome, then if one succeeds in acquiring what one hoped for, intuitively this outcome can be one's achievement, albeit in a diminished sense, even if one is not praiseworthy for it" (2001: 194). Einstein, for example, hoped that his efforts would result in a new theory of gravity. Given that they did, he would have an accurate perception of having achieved what he hoped for, even if he does not deserve praise for his efforts. Achievement, I contend, is best understood in terms of effortful fulfillment of one's goals, desires, and hopes. One can do this, however, without also being praiseworthy in the basic desert sense. Since free will skepticism is consistent with agents exerting effort and working toward their various goals, there is no need to reject the notion of achievement. To say that praiseworthiness is required for true achievement would be question begging without additional argumentation.

I imagine one could argue that there is a necessary link between praiseworthiness and achievement since the concept of achievement entails that when an 
agent achieves a goal they become legitimate targets of praise. I see no reason, however, for thinking this is true. First, while we often associate praiseworthiness with achievement, there is no necessary connection between the two. If we reject the notion of praiseworthiness, as free will skeptics do, a perfectly meaningful conception of achievement remains in place-i.e., one that defines achievement in terms of effort and fulfilling one's goals, hopes, and desires. Second, without praiseworthiness there would still remain (as we saw in the previous section) sound forward-looking reasons for encouraging creative and artistic achievement. Lastly, we do not believe agents are praiseworthy or blameworthy for creative omissions - for example, Einstein failing to have the creative insight that led him to formulate general relativity. This throws into doubt, I believe, the supposed necessary connection between praiseworthiness and achievement. The fact that Einstein hoped that his efforts would result in a new theory of gravity, and they did, means he achieved his goal. But the fact that he could have just as easily failed to achieve his goal by failing to have a creative breakthrough, and this failure would have had nothing to do with a lack of effort on his part, suggests to me that the conditions for praiseworthiness are independent of, and likely more demanding than, the conditions for achievement.

Let me end by considering one last concern. Some critics fear that without a conception of ourselves as credit- or praiseworthy for achieving what makes our lives fulfilled, happy, satisfactory, or worthwhile-i.e., for realizing what Ted Honderich (1988) calls our life-hopes - we will become dismayed. Here again, I follow Pereboom in arguing that while there is an aspect of these life-hopes that may be undercut by skepticism, the skeptical perspective nevertheless leaves them largely intact. Free will skepticism need not instill in us an attitude of resignation to whatever our behavioral dispositions together with environmental conditions hold in store. Suppose, for example, that someone reasonably believes that he has a particular disposition that might well be a hindrance to realizing a life-hope. Let's say that he wants to become a professional concert pianist but is afraid that his stage fright will prevent him from achieving his goal. Because he does not know "whether this disposition will in fact have this effect, it remains open for him - that is, epistemically possible for him - that another disposition of his will allow him to transcend this impediment" (Pereboom 2014: 194). As a result, he might reasonably hope that he will overcome his disposition and achieve his goal. So for the free will skeptic, if he in fact does overcome his stage fright and succeed at his life's-hope, this will count as an achievement-perhaps not the kind of achievement libertarians had in mind, but an achievement in a substantial sense nonetheless.

Pereboom correctly points out that our sense of self-worth is to a non-trivial extent due to features not produced by our volitions, let alone by free will (2014: 
194; see also 2001) - e.g., people "place great value on natural beauty, native athletic ability, and intelligence, none of which have their source in our volition" (2014: 194). Of course we also value voluntary efforts, but it does not matter much to us that these voluntary efforts are also freely willed. Consider how good character comes to be:

It is plausibly formed to a significant degree by upbringing, and the belief that this is so is widespread. Parents regard themselves as having failed in raising their children if they turn out with immoral dispositions, and they typically take great care to bring their children up to prevent such an outcome. Accordingly, people often come to believe that they have the good moral character they do largely because they were raised with love and skill. But those who believe this about themselves seldom experience dismay because of it. We tend not to become dispirited upon coming to understand that good moral character is not our own doing, and that we do not deserve a great deal of praise or credit for it. By contrast, we often feel fortunate and thankful. (Pereboom 2014: 195)

The same is true for creative development. When one realizes the extent to which creative and artistic success, or achievement in one's professional career, is dependent on upbringing, the opportunities that society presents, the support of parents and teachers, and plain luck, one does not typically react with dismay. Rather these thoughts frequently engender thankfulness and a sense of being fortunate. This seems to be how Einstein reacted when he realized: "My own career was undoubtedly determined, not by my own will but by various factors over which I have no control" (1929: 114). Given that this is a common reaction, and at least one open to skeptics to embrace, I maintain that there is no reason to think meaning in life or our senses of achievement would be threatened by free will skepticism.

\section{Conclusion}

In this paper, I have argued that free will skepticism is consistent with a substantial and realistic conception of creativity, S-creativity, which preserves our most important judgments and practices. More specifically, I have argued: (I) since free will skepticism is consistent with attributability, we can legitimately ascribe creativity to agents even if they lack basic desert moral responsibility; (2) given that forward-looking answerability functions without reference to basic desert or the reactive attitudes related to it, free will skeptics can justify calling agents 
to account for immoral behavior and poor creative and artistic judgments; (3) forward-looking grounds also justify encouraging creative development and achievements; (4) since concepts like originality, novelty, and freshness are comparative terms, they are not threatened by free will skepticism; and lastly (5) the sense of fulfillment we experience in achieving our goals would also not be threatened by free will skepticism.

\section{References}

Anglin, W. S. (1990). Free Will and the Christian Faith. Oxford University Press.

Barrett, William (1958). Determinism and Novelty. In Sidney Hook (Ed.), Determinism and Freedom in the Age of Modern Science (46-54).Collier-Macmillan.

Bennett, Jonathan (1980). Accountability. In Z. van Stratten (Ed.), Philosophical Subjects: Essays Presented to P.F. Strawson (89-103). Oxford University Press.

Bok, Hilary (1998). Freedom and Responsibility. Princeton University Press. https://doi. org/10.1515/9781400822737

Caruso, Gregg D. (2012). Free Will and Consciousness: A Determinist Account of the Illusion of Free Will. Lexington Books.

Caruso, Gregg D. (Ed.) (2013). Exploring the Illusion of Free Will and Moral Responsibility. Lexington Books.

Caruso, Gregg D. (2016). Free Will Skepticism and Criminal Behavior: A Public HealthQuarantine Model. Southwest Philosophy Review, 32(1), 25-48. https://doi.org/10.5840/ swphilreview20163214

Caruso, Gregg D. (in press). Free Will Skepticism and Its Implications: An Argument for Optimism. In Elizabeth Shaw and Derk Pereboom (Eds.), Free Will Skepticism in Law and Society. Cambridge University Press.

Caruso, Gregg D., and Stephen Morris (in press). Compatibilism and Retributivist Desert Moral Responsibility: On What Is of Central Philosophical and Practical Importance. Erkenntnis. https://doi.org/10.1007/s10670-016-9846-2

Darwall, Stephen (2006). The Second-Person Standpoint: Morality, Respect, and Accountability. Harvard University Press.

Einstein, Albert (1929, October 26). What Life Means to Einstein: An Interview by George Sylvester Viereck. Saturday Evening Post, 17, 110-117.

Eshleman, Andrew (2014). Moral Responsibility. Stanford Encyclopedia of Philosophy. Retrieved from http://plato.stanford.edu/entries/moral-responsibility/

Fischer, John Martin, and Mark Ravizza (1998). Responsibility and Control: A Theory of Moral Responsibility. Cambridge University Press. https://doi.org/10.1017/ cbo9780511814594

Honderich, Ted (1988). A Theory of Determinism: The Mind, Neuroscience, and Life-Hopes. Oxford University Press.

Kane, Robert (1996). The Significance of Free Will. Oxford University Press.

Levy, Neil (2011). Hard Luck: How Luck Undermines Free Will and Moral Responsibility. Oxford University Press. https://doi.org/10.1093/acprof:oso/9780199601387.001.0001

Levy, Neil (2012). Skepticism and Sanctions: The Benefits of Rejecting Moral Responsibility. Law and Philosophy, 31(5), 477-493. https://doi.org/10.1007/s10982-012-9128-3 
Oshana, Marina (1997). Ascriptions of Responsibility. American Philosophical Quarterly, $34,71-83$.

Pereboom, Derk (2001). Living without Free Will. Cambridge University Press. https://doi. org/10.1017/cbo9780511498824

Pereboom, Derk (2013). Free Will Skepticism and Criminal Punishment. In Thomas Nadelhoffer (Ed.), The Future of Punishment,(49-78). Oxford University Press.

Pereboom, Derk (2014). Free Will, Agency, and Meaning in Life. Oxford University Press. https://doi.org/10.1093/acprof:oso/9780199685516.001.0001

Pereboom, Derk, and Gregg D. Caruso (in press). Hard-Incompatibilist Existentialism: Neuroscience, Punishment, and Meaning in Life. In Gregg D. Caruso and Owen Flanagan (Eds.), Neuroexistentialismism: Meaning, Morals, and Purpose in the Age of Neuroscience. Oxford University Press.

Russell, Paul (2008). Free Will, Art and Morality. Journal of Ethics, 12, 307-325. https://doi. org/10.1007/s10892-008-9037-8

Scanlon, Thomas (1998). What We Owe to Each Other. Harvard University Press.

Shoemaker, David (2011). Attributability, Answerability, and Accountability: Toward a Wider Theory of Moral Responsibility. Ethics, 121(3), 602-632. https://doi. org/10.1086/659003

Strawson, Galen (1994). The Impossibility of Moral Responsibility. Philosophical Studies, 75(1), 5-24. https://doi.org/10.1007/BF00989879

Strawson, Galen (2010). Freedom and Belief (Rev. ed.). Oxford University Press. https:// doi.org/10.1093/acprof:oso/9780199247493.001.0001

Strawson, P. F. (1962). Freedom and Resentment. Proceedings of the British Academy, 48, $1-25$.

Wallace, R. Jay (19f94). Responsibility and the Moral Sentiments. Harvard University Press.

Waller, Bruce (2011). Against Moral Responsibility. MIT Press. https://doi.org/10.7551/mitpress/9780262016599.001.0001

Waller, Bruce (2015). The Stubborn System of Moral Responsibility. MIT Press. https://doi. org/10.7551/mitpress/9780262028165.001.0001

Watson, Gary (1996). Two Faces of Responsibility. Philosophical Topics, 24(2), 227-248. https://doi.org/10.5840/philtopics199624222 
